\title{
Improved dissolution of a poorly water soluble drug in solid dispersions with polymeric and non-polymeric hydrophilic additives
}

\author{
GARIMA CHAWLA \\ ARVIND K. BANSAL* \\ Department of Pharmaceutical Technology \\ (Formulations) \\ National Institute of Pharmaceutical \\ Education and Research (NIPER) \\ Sector 67, Phase X, S.A.S. Nagar \\ Punjab-160062, India
}

\begin{abstract}
Irbesartan (IBS) is a hydrophobic drug with poor aqueous solubility and dissolution rate. Solid dispersions (SDs) of IBS were prepared with both small molecules (tartaric acid and mannitol) and polymeric additives (polyvinylpyrrolidone, PVP, and hydroxypropyl methylcellulose, HPMC). A 9.5 and 7 folds enhancement in solubility over the crystalline form $\left(14.6 \mu \mathrm{g} \mathrm{mL}^{-1}\right)$ was observed for tartaric acid $\left(138 \mu \mathrm{g} \mathrm{mL}^{-1}\right)$ and PVP $\left(103 \mu \mathrm{g} \mathrm{mL}^{-1}\right)$, respectively. Powder X-ray diffraction confirmed that IBS existed in the glassy state in all cases, even with excipients having low glass transition temperature. Thermal methods (differential scanning calorimetry and hot stage microscopy) were used to evaluate the miscibility of the drug and additives. These techniques suggested that tartaric acid led to generation of "amorphous solutions « in contrast to "amorphous suspensions « in other three cases. The in vitro dissolution of IBS depended on the additive load and increased with increasing concentration in the case of tartaric acid, an acidifying excipient. The results indicate the suitability of even small molecules for providing solubility benefits, which can be attributed to the good glass forming ability and reasonable ability of IBS to remain in the glassy state.
\end{abstract}

Keywords: irbesartan, solid dispersion, amorphous form, solubility, dissolution rate

Aqueous solubility of a drug can be a critical limitation to its oral absorption. Lipophilic molecules, especially those belonging to the biopharmaceutics classification system (BCS) class II and IV, dissolve slowly, poorly and irregularly, and hence pose serious delivery challenges, like incomplete release from the dosage form, poor bioavailability, increased food effect, and high inter-patient variability (1). Many solubilization techniques have been described that either change the nature of the solvent environment (co-

\footnotetext{
* Correspondence, e-mail: akbansal@niper.ac.in
} 
G. Chawla and A. K. Bansal: Improved dissolution of a poorly water soluble drug in solid dispersions with polymeric and non-polymeric hydrophilic additives, Acta Pharm. 58 (2008) 257-274.

-solvent systems, emulsions, micellization) or the chemical identity of the dissolved solute (salt formation, complexation, pro-drugs) (2).

Alteration of the solid state at the particle or molecular level involves a physical change in the drug and is an attractive option for improving drug solubility (3).

Particle size reduction by micronization or nanonization can enhance the dissolution rate; however, the apparent solubility remains unaltered. At the molecular level, polymorphs offer a limited solubility advantage because of a small difference in free energy (4). In contrast, amorphous systems with excess thermodynamic properties and lower energetic barrier can offer significant solubility benefits (4). This solubility benefit can be further enhanced by preparing solid dispersions (SDs). SDs contribute by slowing devitrification, enhancing wettability and modulating the properties of the solvent (5).

The aim of the present study was to examine the solubility and dissolution properties of SDs of irbesartan (IBS), prepared with small molecules such as tartaric acid and mannitol and polymeric additives like polyvinylpyrrolidone (PVP) and hydroxypropyl methylcellulose (HPMC). IBS, 2-butyl-3-[[29-(1H-tetrazol-5-yl) [1,19-biphenyl]-4-yl] methyl]1,3-diazaspiro[4,4] non-1-en-4-one (Fig. 1), is a potent long acting non-peptide AII receptor antagonist used in the treatment of hypertension (6). IBS was chosen as a model candidate because of its low dissolution rate and solubility-limited bioavailability (7). We have previously reported that the amorphous form of IBS improves solubility over the crystalline form (7).

\section{EXPERIMENTAL}

\section{Materials}

IBS (purity $>99 \%$ ) was gift of Dr Reddy's Labs (India). All high-performance liquid chromatography (HPLC) solvents were of HPLF grade and procured from Merck (Germany), tartaric acid (DL) was obtained from s.d. Fine-chem Ltd. (India), mannitol from Qualigens (India), poly(vinylpyrrolidone) (PVP) K30 was obtained from ISP Technologies (USA), and hydoxypropyl methylcellulose (HPMC) K100LV was obtained from Colorcon Asia Pvt. Ltd. (India). All other chemicals were of analytical grade. The materials were used as received without any further purification.

\section{Preparation of amorphous IBS by quench cooling}

Amorphous IBS was prepared by melting the drug in a stainless steel beaker at $200{ }^{\circ} \mathrm{C}$ and subsequent quench cooling of the melt over crushed ice. The quench-cooled product was ground, sieved (BSS No. 60, mesh size $250 \mu \mathrm{m}$ ) and found to be amorphous by powder X-ray diffraction (PXRD) immediately after preparation. HPLC analysis (method described below) confirmed that no degradation had occurred during the procedure.

\section{Generation of solid dispersions of IBS}

As discussed in previous section, quench cooling was used for preparation of SDs of IBS. Temperature was controlled in dependence on the melting temperature of the 
G. Chawla and A. K. Bansal: Improved dissolution of a poorly water soluble drug in solid dispersions with polymeric and non-polymeric hydrophilic additives, Acta Pharm. 58 (2008) 257-274.

drug/excipients. Physical mixtures of the drug and additives were prepared by geometric mixing, by triturating using the mortar and pestle. The quench-cooled product was ground, sieved (BSS No. 60 mesh size, $250 \mu \mathrm{m}$ ) and used immediately after preparation. Initially, $20 \%(\mathrm{~m} / \mathrm{m})$ of the excipient (tartaric acid, mannitol, PVP and HPMC) was used. The effect of the concentration of tartaric acid and PVP (selected excipients) was also studied.

\section{Powder X-ray diffraction (PXRD)}

PXRD patterns of freshly prepared powdered samples (under controlled temperature and humidity conditions) were recorded at room temperature on Bruker's D8 Ad-<smiles>CCCCC1=NC2(CCCC2)C(=O)N1Cc1ccc(-c2ccccc2-c2nn[nH]n2)cc1</smiles><smiles>O=C(O)C(O)C(O)C(=O)O</smiles>

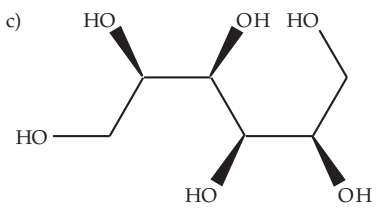

d)
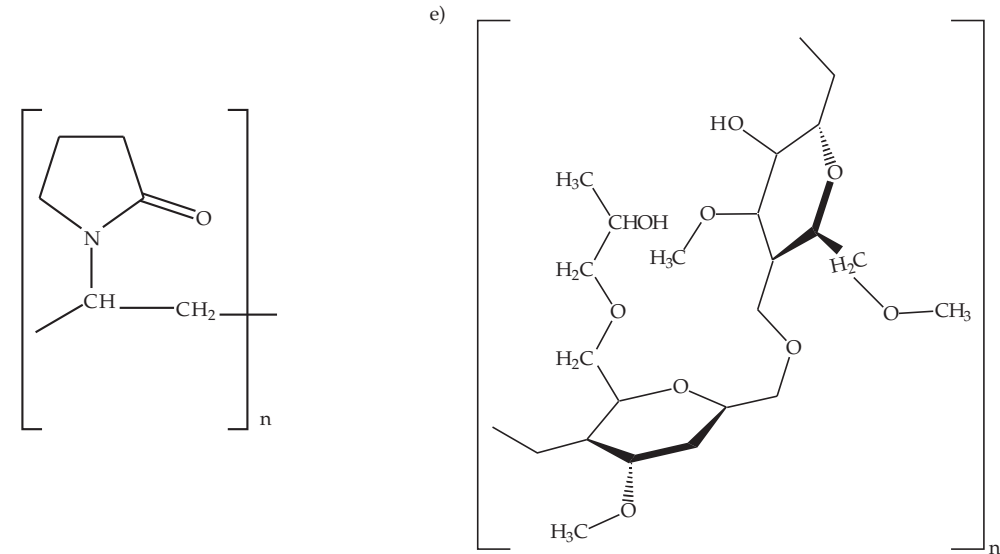

Fig. 1. Chemical structure of IBS and additives: a) IBS, b) tartaric acid, c) mannitol, d) PVP, e) HPMC. 
G. Chawla and A. K. Bansal: Improved dissolution of a poorly water soluble drug in solid dispersions with polymeric and non-polymeric hydrophilic additives, Acta Pharm. 58 (2008) 257-274.

vance diffractometer (Germany) with $\mathrm{CuK} \alpha$ radiation $(1.54 \AA$ ), at $40 \mathrm{kV}, 40 \mathrm{~mA}$, passing through a nickel filter with a divergence slit $\left(0.5^{\circ}\right)$, antiscattering slit $\left(0.5^{\circ}\right)$, and receiving slit $(1 \mathrm{~mm})$. The diffractometer was equipped with a $2 \theta$ compensating slit and was calibrated for accuracy of peak positions with a silicon pellet. Samples were mounted either on a 25-mm holder made of polymethyl methacrylate (PMMA) or a zero background small sample holder, depending on sample size, and were subjected to X-ray powder diffraction analysis in continuous mode with a step size of $0.01^{\circ}$ and step time of 1 second over an angular range of 3 to $40^{\circ} 2 \theta$. Sample holders were rotated in a plane parallel to their surface at $30 \mathrm{rpm}$ during the measurements. Obtained diffractograms were analyzed with DIFFRACplus EVA (ver. 9.0) diffraction software.

\section{Differential scanning calorimetry (DSC)}

Thermal transitions were determined using a Mettler Toledo 821e DSC (Mettler Toledo, Switzerland) operating with version 5.1 of Stare software using (4-6 mg) samples in aluminium pans with pierced lids at heating rates of $20^{\circ} \mathrm{C} \mathrm{min}-1$ under nitrogen purge at $80 \mathrm{~mL} \mathrm{~min}^{-1}$. The instrument was calibrated for temperature and heat flow using high purity indium and zinc standards.

\section{Hot stage microscopy (HSM)}

Thermal transitions were visually observed under a Leica DMLP polarized microscope (Leica Microsystems, Germany) equipped with Leica LMW hot stage. Photomicrographs were acquired using a Leica DC 300 camera and analyzed using Leica IM 50 (version 1.20) software.

\section{High performance liquid chromatography}

The HPLC method for solubility and dissolution rate studies has been described previously (6). All solubility and dissolution samples were analyzed on an HPLC system (Shimadzu, Japan) using Lichrospher® 100 RP-18e $(5 \mu \mathrm{m})$ (Merck, Germany) analytical column under isocratic conditions at a flow rate of $0.7 \mathrm{~mL} \mathrm{~min}{ }^{-1}$ at $25{ }^{\circ} \mathrm{C}$. Injection volume $10 \mu \mathrm{L}$ and effluent were monitored at $275 \mathrm{~nm}$. The mobile phase was $10 \mathrm{mmol} \mathrm{L}^{-1}$ potassium dihydrogen orthophosphate/methanol/acetonitrile (15:75:10) $(\mathrm{pH} 2.5)$.

\section{In vitro dissolution studies}

Dissolution experiments of crystalline, amorphous and SD samples were carried out in triplicate with a United States Pharmacopeia Apparatus I (basket-type) (TDT-08L, Electrolab, India), employing $900 \mathrm{~mL}$ of deionized water and $0.1 \mathrm{~mol} \mathrm{~L}^{-1} \mathrm{HCl}$, at a temperature of $37 \pm 0.5^{\circ} \mathrm{C}$, at rotational speed of $100 \mathrm{rpm}$. Sample mass maintaining the sink conditions (i.e., three times the solubility) was filled into hard gelatin capsule shells. At predetermined intervals $(5,15,30,60,90,120,240,360$ and $480 \mathrm{~min})$, samples were withdrawn (with replacement of equal volume of an pre-warmed medium into the vessel), filtered, appropriately diluted and analyzed for drug concentration using HPLC. It was first confirmed that the method was specific for the analysis of IBS and additives did not interfere with the drug. In vitro dissolution studies of SDs were also performed using 
G. Chawla and A. K. Bansal: Improved dissolution of a poorly water soluble drug in solid dispersions with polymeric and non-polymeric hydrophilic additives, Acta Pharm. 58 (2008) 257-274.

different concentrations of excipients, tartaric acid and PVP [10, 20, 40, 50, 60 and 80\% $(m / m)]$.

The effects of rotational speed (25, 50 and $100 \mathrm{rpm})$, sample fill mass in the capsule and degassing of media on the dissolution rate were also studied.

\section{Solubility studies}

The dynamic solubility of crystalline, amorphous and various SDs of IBS was determined by adding excess solid (150 $\mathrm{mg}$ ) to $100 \mathrm{~mL}$ deionized water placed in stoppered conical flasks, pre-equilibrated to $37 \pm 0.5^{\circ} \mathrm{C}$. The flasks were mechanically shaken in a shaking water bath (SW 23, Julabo Labortechnik GmbH, Germany) at $100 \mathrm{rpm}$. At pre-determined intervals, an aliquot was withdrawn, filtered through a $0.45-\mu \mathrm{m}$ syringe filter, diluted and analyzed by HPLC. Simultaneously, the solid phase was analyzed by PXRD.

Solubility studies of the physical mixture (prepared by geometric mixing) of drug-excipient and in solution of $20 \%(\mathrm{~m} / \mathrm{m})$ excipient in water were performed.

\section{RESULTS AND DISCUSSION}

IBS is a non-polar compound with a partition coefficient (octanol/water) of 10.1 at $\mathrm{pH} 7.4$, and low aqueous solubility $\left(<0.1 \mathrm{mg} \mathrm{mL}^{-1}\right.$ in water at $\left.25^{\circ} \mathrm{C}\right)$. The crystalline form A crystallizes with 2 hydrophobic channels containing aliphatic chains, leading to weak solubility and strong aggregation in water. Previous work by the authors (6) illustrated a 2.5 fold higher »apparent « solubility of amorphous IBS over its crystalline phase. Lower heat of solution $\left(\Delta H_{S}\right)$ for amorphous IBS $\left(-12.6 \mathrm{~kJ} \mathrm{~mol}^{-1}\right)$ in comparison to crystalline form $\left(-37.6 \mathrm{~kJ} \mathrm{~mol}^{-1}\right)$, absence or reduced crystal packing energy and higher Gibb's free energy $(\Delta G)$ indicated the ease and spontaneity of IBS molecules to leave the disordered amorphous system and be molecularly dispersed in the solvent (8).

Conventionally, this enhanced solubility of the amorphous system would translate into an increased dissolution rate. However, dissolution rate of amorphous IBS was lower than the dissolution rate of the crystalline form of IBS, in water and in $0.1 \mathrm{~mol} \mathrm{~L}^{-1}$ $\mathrm{HCl}$ (Fig. 2a). Visual observation revealed that the amorphous material had formed a hard plug that prevented penetration of water to deeper layers (Fig. 2b). This was confirmed by the cross sectional view of the plug, wherein the outer surface was wet, and the inner portion was found to be comparatively dry. The residual material at the end of the eight hours long dissolution experiment was characterized by PXRD and polarized light microscopy. The outer sample surface of IBS indicated partial crystallization as it was evident from the appearance of sharp diffraction peaks. The sample core essentially retained the amorphous nature (Fig. 2c). Similar observations have been made previously with drugs like ritonavir and carvedilol wherein amorphous forms exhibited incomplete release in comparison with the crystalline form; however, generation of SD improved the dissolution rate $(10,11)$. Higher apparent solubility of amorphous IBS at all $\mathrm{pH}$ values and a higher intrinsic dissolution rate (6) suggested that IBS could be a good candidate for dissolution rate improvement through SD formation. 
G. Chawla and A. K. Bansal: Improved dissolution of a poorly water soluble drug in solid dispersions with polymeric and non-polymeric hydrophilic additives, Acta Pharm. 58 (2008) 257-274.

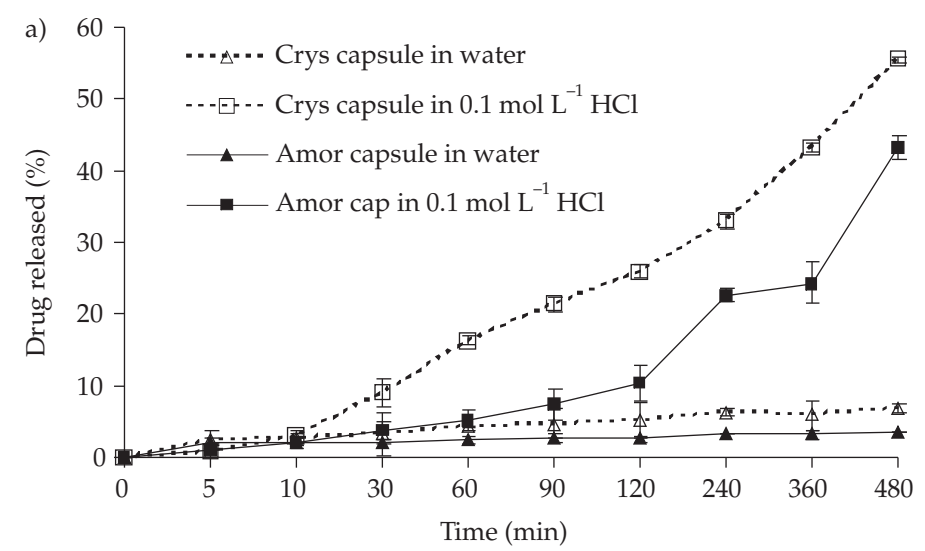

b)
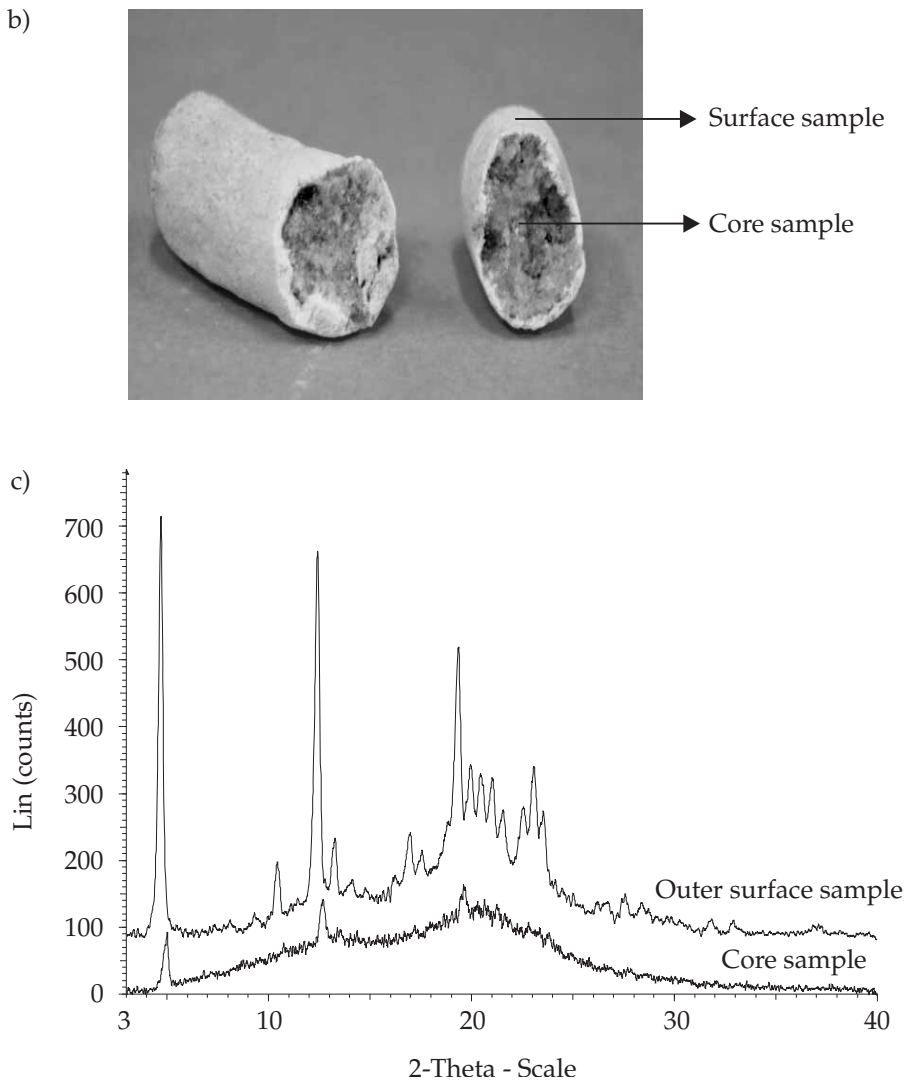

Fig. 2. In vitro dissolution-time profile of amorphous IBS: a) concentration time profile of crystalline and amorphous IBS, b) plug formed in amorphous IBS in dissolution media, c) PXRD pattern of residual dissolution samples. 
G. Chawla and A. K. Bansal: Improved dissolution of a poorly water soluble drug in solid dispersions with polymeric and non-polymeric hydrophilic additives, Acta Pharm. 58 (2008) 257-274.

Amorphous materials have the ability to form molecular level single-phase dispersions with pharmaceutical excipients. These "amorphous alloys « permit creation of custom pharmaceuticals with unique properties by selection of appropriate interacting excipients (12). Numerous reports have cited dissolution rate improvement of poorly soluble drugs through production of SDs using various hydrophilic carriers, such as polyvinylpyrrolidone, hydroxypropyl methylcellulose, sugars, and mannitol (13-16). Dispersions of IBS were formed using two non-polymeric excipients, tartaric acid and mannitol, and two polymeric excipients, PVP and HPMC.

Fig. 3a exhibits the needle-shaped crystals of the drug. Amorphous material on the other hand exhibits irregularly shaped birefringent particles. SDs of IBS were formed using quench cooling, which led to generation of a non-birefringent glassy material observed under polarized light (Fig. 3b). All freshly prepared dispersions, except the one with mannitol, exhibited a halo pattern in PXRD, thus confirming their amorphous nature. Comparison of PXRD patterns of IBS-mannitol dispersions revealed that the peaks matched that of mannitol and peaks corresponding to IBS were absent (Fig. 3c). Hence, it can be inferred that IBS was present in the amorphous state in the dispersion and mannitol was in the crystalline state. Similar behavior has been reported for mannitol with other drug substances in earlier studies $(14,17)$.

DSC analysis of crystalline IBS showed a single sharp fusion endotherm in the temperature range of $183-190( \pm 0.5){ }^{\circ} \mathrm{C}\left(\Delta H_{\mathrm{f}}=107 \pm 2 \mathrm{~J} \mathrm{~g}^{-1}\right)$ at a heating rate of $20{ }^{\circ} \mathrm{C} \mathrm{min}-1$. Quench-cooled IBS exhibited a glass transition event at $71.7 \pm 1.0^{\circ} \mathrm{C}$ (onset $T_{\mathrm{g}}$ ) and no other exothermic peak of crystallization or endothermic peak of melting was observed. Even when heated at a slow rate of $1{ }^{\circ} \mathrm{C} \mathrm{min}^{-1}$, amorphous IBS did not crystallize spontaneously, thus suggesting lack of crystallization tendency of amorphous IBS. IBS exhibited a $T_{\mathrm{g}} / T_{\mathrm{m}}$ of 0.75 and is expected to be a relatively good glass former (10).

The nature of SD was also studied using HSM and DSC by performing studies on both physical mixtures and SDs. In DSC, changes in the melting endotherm of the drug and single $T_{\mathrm{g}}$ at a temperature between $T_{\mathrm{g}}$ values of both components is evidence for formation of a miscible system (18). SDs can thus be classified as an "amorphous solution « (with single $T_{\mathrm{g}}$ ), »amorphous suspension « (two $\left.T_{\mathrm{g}} \mathrm{s}\right)$ or crystalline suspension $\left(T_{\mathrm{g}}\right.$ and melting event).

Unlike mannitol, tartaric acid exhibited complete miscibility with molten IBS. However, these events cannot be resolved with DSC as the melt endotherms may be a mixture of the heat of fusion and heat of solution (Fig. 3d). HSM clearly allowed visualization of the events, melting and dissolution of one component in the melt of the other (Fig. 3e). On a hot stage microscope, tartaric acid melted in the range of $180-207^{\circ} \mathrm{C}$. In the presence of IBS, a single event of melting of both components was observed at 170-180 ${ }^{\circ} \mathrm{C}$, resulting in a clear melt. This indicated miscibility of the two components. In DSC, quench cooled IBS-tartaric acid dispersions showed a single $T_{\mathrm{g}}$ at $79^{\circ} \mathrm{C}\left(\mathrm{T}_{\mathrm{g}}\right.$ onset $)$, thus proving formation of an »amorphous solid solution «. However, the glass transition event of this phase was observed at a temperature higher than the temperature expected based on the composition (Table I). Such an increase in $T_{\mathrm{g}}$ has been observed previously as a result of ionic and heteromolecular interactions $(14,19,20)$. Theoretical $T_{\mathrm{g}}$ of the drug-additive mix (Table I) was calculated using the Gordon-Taylor/Kelley-Bueche equation (21): 
G. Chawla and A. K. Bansal: Improved dissolution of a poorly water soluble drug in solid dispersions with polymeric and non-polymeric hydrophilic additives, Acta Pharm. 58 (2008) 257-274.

$$
T_{g m i x}=\frac{w T_{g 1}+K w_{2} T_{g 2}}{w_{1}+K w_{2}}
$$

where subscripts represent the two components (drug and additive), $w$ represents their mass fractions, and $K$ is the ratio of their free volumes given by Eq. (2), where $\rho$ is the density of the two materials (obtained from literature):

$$
K=\frac{\left(\rho_{1} T_{g 1}\right)}{\left(\rho_{2} T_{g 2}\right)}
$$

With mannitol, molten additive gave rise to an immiscible liquid phase within the molten drug (Figs. 3f,g). This immiscibility was observed in HSM as droplets of mannitol within the melt of IBS. In addition, mannitol recrystallizes quickly on a hot stage microscope upon melt cooling (Fig. 3h), thus giving sharp peaks in PXRD. Pure mannitol exhibited a sharp melting endotherm in the temperature range of $164-176{ }^{\circ} \mathrm{C}$. Two $T_{\mathrm{g}} \mathrm{S}$, at 59 and $71{ }^{\circ} \mathrm{C}$ (Fig. 3i) in the case of quench cooled IBS-mannitol dispersions suggested the formation of an »amorphous suspension«. With time, when stored under room temperature and humidity, this dispersion can be categorized as a »crystalline suspension « containing amorphous drug and crystalline mannitol. Similar behavior of D-mannitol has been observed by other authors with drugs such as sulphonamides, tolbutamide, isopropylantipyrin and oxazepam (17).

Polymeric excipients PVP and HPMC did not mix with the drug melt in their molten state. In DSC, no melting endotherms were observed with pure PVP and HPMC due to their amorphous nature. Immiscibility was observed on both HSM and DSC. Droplets of softened PVP were observed in the melt of the drug (Fig. 3j), while solid particles of HPMC were entrapped in the melt droplets of the drug (Fig. 3k). HPMC remained as a solid until a temperature of $230{ }^{\circ} \mathrm{C}$. In quench cooled dispersions $T_{\mathrm{g}} \mathrm{s}$ were observed at about $81{ }^{\circ} \mathrm{C}$ for IBS and near $167{ }^{\circ} \mathrm{C}$ for the excipients (Fig. 31). High viscosity of polymers has been reported previously to limit the miscibility of drugs with polymers (22). These dispersions can be also classified as "amorphous suspensions" containing two, partial or complete, amorphous phases (23).

IBS, a hydrophobic molecule, achieves an equilibrium aqueous solubility of $14.6 \mu \mathrm{g}$ $\mathrm{mL}^{-1}$ in about $480 \mathrm{~min}$. The crystalline material adhered to the walls of the flask and

\begin{tabular}{|c|c|c|c|}
\hline Additive & $T_{\mathrm{g}}\left({ }^{\circ} \mathrm{C}\right)$ & Theoretical $T_{\text {gmix }}$ of SD $\left({ }^{\circ} \mathrm{C}\right)$ & Peak concentration $\left(\mu \mathrm{g} \mathrm{mL}^{-1}\right)$ \\
\hline Tartaric acid & 18 & 63 & 138 \\
\hline Mannitol & 11 & 60 & 55 \\
\hline PVP & 168 & 87 & 103 \\
\hline HPMC & 150-180 & $87^{a}$ & 81 \\
\hline
\end{tabular}

Table I. $\mathrm{T}_{g}$ of additives and theoretical $\mathrm{T}_{g}$ of SDs

\footnotetext{
a Average $T_{\mathrm{g}}$ taken
} 
G. Chawla and A. K. Bansal: Improved dissolution of a poorly water soluble drug in solid dispersions with polymeric and non-polymeric hydrophilic additives, Acta Pharm. 58 (2008) 257-274.

a)

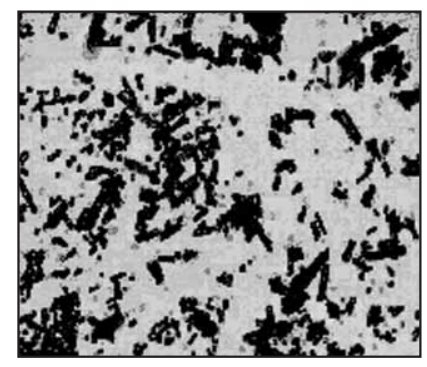

b)

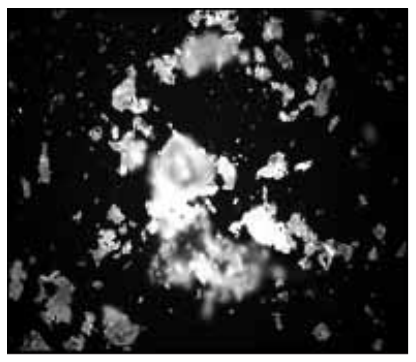

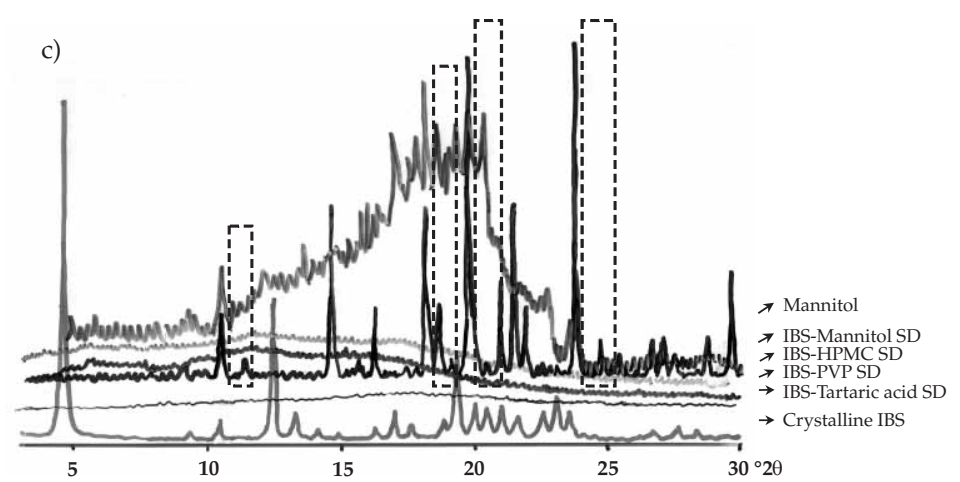

d)

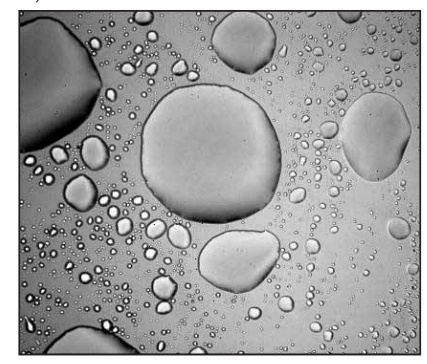

f)

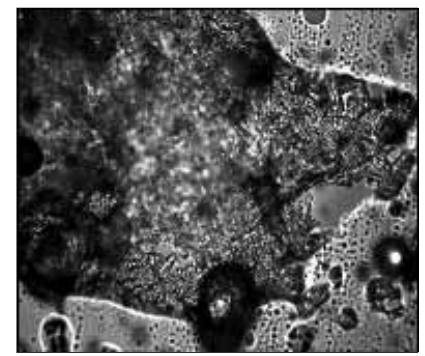

e)

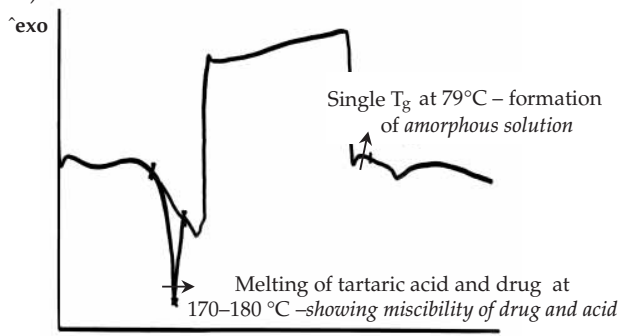

Temperature $\longrightarrow$

g)

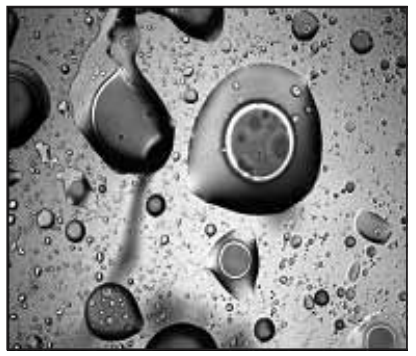


G. Chawla and A. K. Bansal: Improved dissolution of a poorly water soluble drug in solid dispersions with polymeric and non-polymeric hydrophilic additives, Acta Pharm. 58 (2008) 257-274.

h)

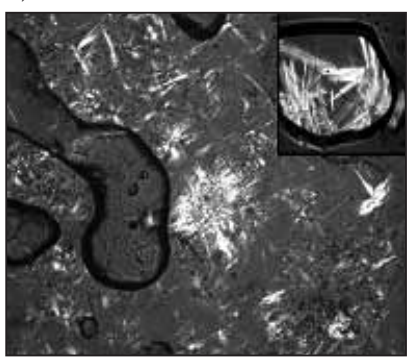

j)

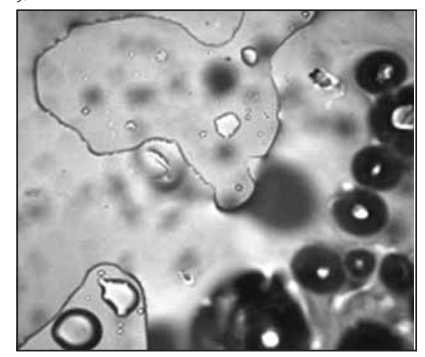

i)

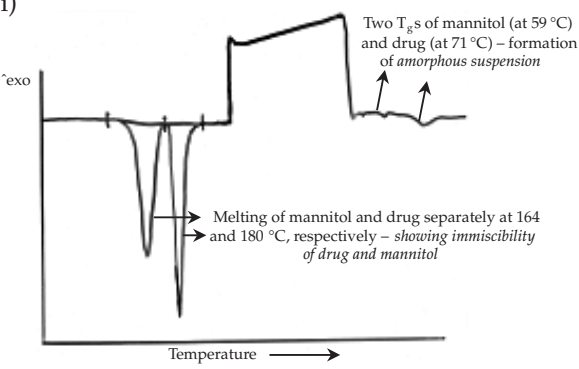

k)

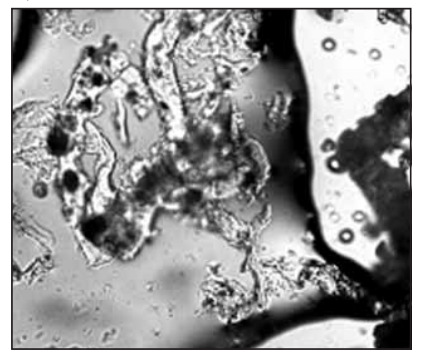

1)

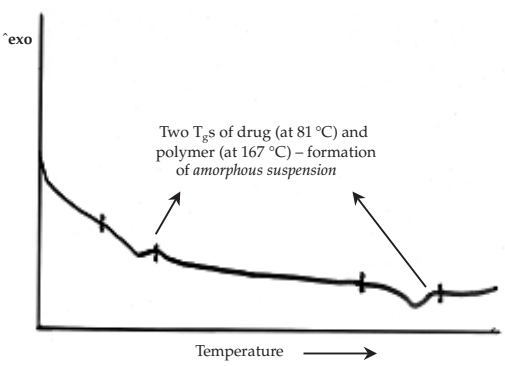

Fig. 3. Thermal and PXRD characterization of crystalline, quench cooled SD and IBS-additive (20\%, $m / m$ ) physical mixture: a) crystalline IBS under HSM, 100x, RT, b) SD prepared using quench cooling under HSM, 100x, RT, c) PXRD of SD and mannitol (dashed boxes highlight the peaks of mannitol in IBS-mannitol SD), d) IBS-tartaric acid physical mixture under HSM, 200x, $200{ }^{\circ} \mathrm{C}$, e) DSC curve of IBS-tartaric acid physical mixture and SD, f) IBS-mannitol under HSM, 200x $190{ }^{\circ} \mathrm{C}, \mathrm{g}$ ) IBS-mannitol under HSM, 200x, $200{ }^{\circ} \mathrm{C}$, h) IBS-mannitol cooled after melting under HSM, 200x, 185 ${ }^{\circ} \mathrm{C}$ (inset shows a magnified view at 630x), i) DSC curve of IBS-mannitol physical mixture and SD, j) IBS-PVP under HSM, 200x, $203{ }^{\circ} \mathrm{C}$, k) IBS-HPMC under HSM, 200x, $\left.223{ }^{\circ} \mathrm{C}, 1\right)$ DSC curve of IBS-PVP SD.

floated on the surface of medium. Glassy IBS, on the other hand, sank in water in about $10 \mathrm{~min}$ and exhibited enhanced peak solubility of $36.4 \mu \mathrm{g} \mathrm{mL}^{-1}$. This initial solubility peak value started to drop after $60 \mathrm{~min}$, became equivalent to the crystalline form in 120 min and in 480 min reduced to $10 \mu \mathrm{g} \mathrm{mL}^{-1}$ (73\% drop from peak), which is even less 
than the pure crystalline form, due to formation of the lower solubility polymorph-form B (6). SDs prepared using both types of excipients showed significant enhancement in solubility over the crystalline and amorphous forms (Fig. 4). As observed from Fig. 4, maximum enhancement in solubility was achieved using tartaric acid (solubility peak $138 \mu \mathrm{g} \mathrm{mL}-1$ in $90 \mathrm{~min}$ ). Mannitol exhibited the least improvement in solubility peak (55 $\mu \mathrm{g} \mathrm{mL} \mathrm{m}^{-1}$ in $\left.30 \mathrm{~min}\right)$, but was still higher than amorphous or crystalline IBS. In case of polymeric excipients, PVP (solubility peak $103 \mu \mathrm{g} \mathrm{mL}^{-1}$ in $240 \mathrm{~min}$ ) exhibited higher solubility than HPMC (solubility peak $81 \mu \mathrm{g} \mathrm{mL}^{-1}$ in $60 \mathrm{~min}$ ). Even at a concentration of $20 \%$ $(\mathrm{m} / \mathrm{m})$, a marked solubility advantage was observed with tartaric acid and PVP. Another interesting observation relating to polymeric excipients was the duration of solubility peak. The drop in solubility values after attaining »metastable« solubility was less in polymeric dispersions compared to dispersions of non-polymeric molecules. Polymeric excipients exhibited a negligible drop from the solubility peak values (PVP 1.2; HPMC 1.1 folds) in contrast to the 8.2 fold drop from the solubility peak value in 480 min in pure amorphous IBS.

Excipients in SDs can affect solubility primarily by two mechanisms: (i) capacity to stabilize amorphous drug against water-induced crystallization, or (ii) specific contribution towards the solubilization process.

Water, which is a strong plasticizer, leads to reduction in $T_{\mathrm{g}}$ of the system causing devitrification. Polymeric materials have been reported to have higher $T_{\mathrm{g}}$ values (PVP $168{ }^{\circ} \mathrm{C}, \mathrm{HPMC} 168^{\circ} \mathrm{C}$ ) and would therefore act as better stabilizers compared to small molecules that have lower $T_{\mathrm{g}}$ values (17). The high $T_{\mathrm{g}}$ values of polymers PVP and HPMC may thus induce an anti-plasticization effect along with improved wettability due their hydrophilic nature. Polymers may help in maintaining supersaturation by coating and passivating small embryos to arrest growth by preventing condensation of drug molecules onto the surface embryos (24). This may be the probable reason for lower drop in solubility from the peak value in case of dispersions prepared using polymers. Both PVP and

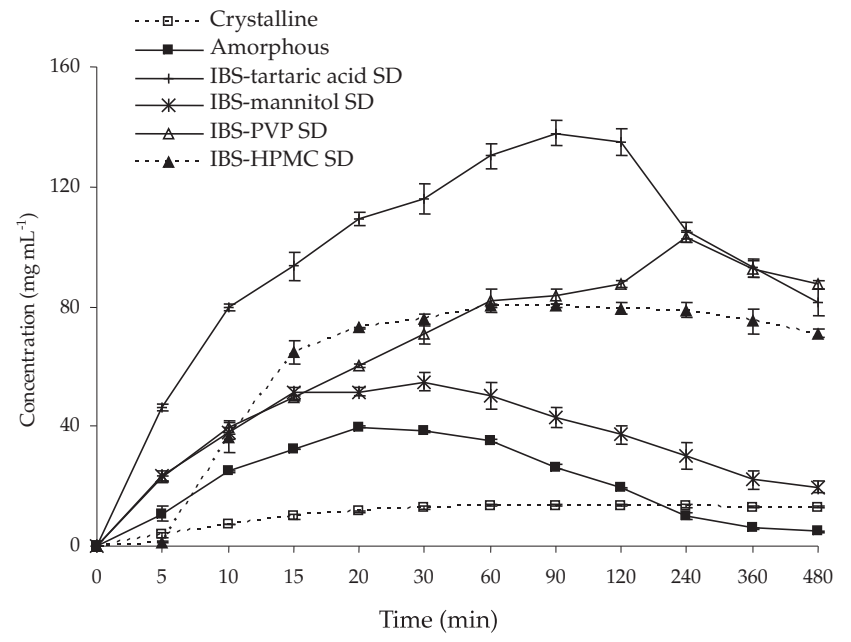

Fig. 4. Concentration-time profiles of crystalline, amorphous and SDs of IBS [using $20 \%(\mathrm{~m} / \mathrm{m})$ of the excipient]. SD bars for $n=3$. 
G. Chawla and A. K. Bansal: Improved dissolution of a poorly water soluble drug in solid dispersions with polymeric and non-polymeric hydrophilic additives, Acta Pharm. 58 (2008) 257-274.

HPMC showed almost similar solubility profiles. Moreover, being hydrophilic in nature the polymers would not act as rate controlling parameters for dissolution.

Small molecules with low $T_{\mathrm{g}}$ values are not expected to stabilize the amorphous system against water-induced recrystallization. Tartaric acid was found to decrease the $\mathrm{pH}$ of the solution [ $\mathrm{pH}$ of water after addition of $20 \%(\mathrm{~m} / \mathrm{m})$ tartaric acid was 2.27, i.e. a drop of about 6.7 units] and as IBS exhibited improved solubility at lower $\mathrm{pH}$ values (6), solubilization would be aided by this drop in $\mathrm{pH}$. As reported earlier, at low $\mathrm{pH}$ values IBS exhibited high solubility and after attaining the peak, a plateau was achieved with no drop in solubility. A similar case was that of tartaric acid and only a 1.7 fold drop in solubility was observed. In contrast, no change in $\mathrm{pH}$ was observed with the other excipient-mannitol. Sugars and highly soluble polyolic materials act as »water structure formers«. These substances have been reported to strengthen the intermolecular hydrogen bonding in water, making it more hydrophobic, and thus favor the dissolution of a poorly hydrosoluble drug (25).

Two additives, namely tartaric acid and PVP, were selected as representatives of small molecules and polymers, respectively. The additive concentration was found to play a significant role in the solubility of dispersions, especially for tartaric acid. In case of tartaric acid SDs, it was observed that the concentration of tartaric acid controlled both the time taken to reach the peak and the peak solubility values (Fig. 5a). Peak solubility and time taken to achieve this peak was found to increase with the increasing concentration of tartaric acid. In addition, $\mathrm{pH}$ values were dependent on concentration of tartaric acid, with the highest of 2.33 with $10 \%$ and a minimum of 1.96 with $80 \%(\mathrm{~m} / \mathrm{m})$ of tartaric acid. This dependence of performance on the content of additive in tartaric acid dispersions may be due to the $\mathrm{pH}$ shift caused by the acid. A marginal change in $\mathrm{pH}$ may be sufficient to influence the solubility of IBS owing to its strong $\mathrm{pH}$ dependent solubility, as observed in the previous report (6). On the other hand, in the case of PVP, differences in solubility were observed at $20 \%(\mathrm{~m} / \mathrm{m})(105 \mu \mathrm{g} \mathrm{mL}-1$ in $240 \mathrm{~min})$ and $80 \%$ $(\mathrm{m} / \mathrm{m})\left(169 \mu \mathrm{g} \mathrm{mL}^{-1}\right.$ in $\left.360 \mathrm{~min}\right)$. Solubility values in PVP at different concentrations remained within a close range, with a sudden rise seen at $80 \%(\mathrm{~m} / \mathrm{m})$.

PXRD of dispersions was performed and it was observed that IBS was amorphous at all concentrations. Halo pattern was observed in all SDs; however, in dispersions containing more than $40 \%(\mathrm{~m} / \mathrm{m})$ tartaric acid, few diffraction peaks of low intensity were observed. The peaks increased both in number and intensity with the increase in concentration. IBS was present in amorphous form at all concentrations since no peaks of IBS were observed in PXRD.

The PXRD and HSM studies suggested that tartaric acid was miscible with IBS at all concentrations, but at high concentrations, tartaric acid crystallized on cooling. However, being a relatively stable molecule in the glassy state, IBS does not crystallize out even with a low $T_{\mathrm{g}}\left(18^{\circ} \mathrm{C}\right)$ substance like tartaric acid. Also, the absence of endothermic peak in DSC corresponding to IBS melting indicated that the drug was dispersed amorphously. In the case of PVP, a halo pattern was observed in all cases. However, on the hot stage microscope, at concentration higher than $20 \%(\mathrm{~m} / \mathrm{m})$, PVP did not melt and remained as solid particles dispersed in the drug melt.

The relative contribution of additives, present either in solid phase (in drug-additive mixtures, PM) or in solution (in pre-dissolved state in water, phase solubility), was ascertained by studying the solubilities of the physical mixtures and by dissolving the 
G. Chawla and A. K. Bansal: Improved dissolution of a poorly water soluble drug in solid dispersions with polymeric and non-polymeric hydrophilic additives, Acta Pharm. 58 (2008) 257-274.

a)

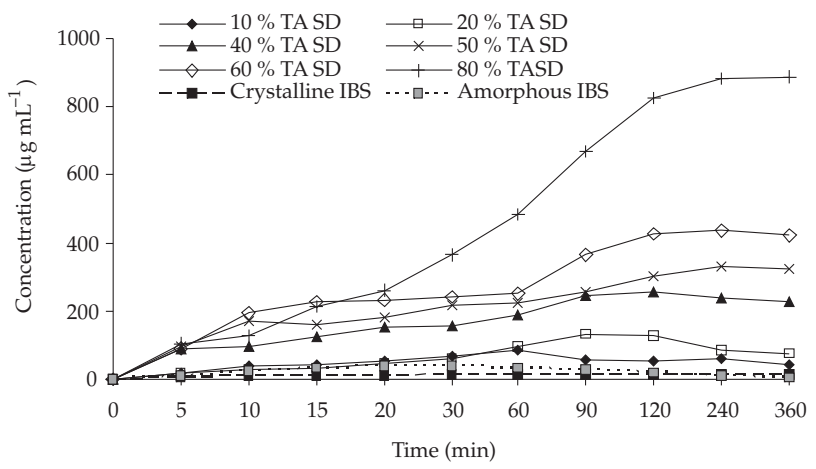

b)

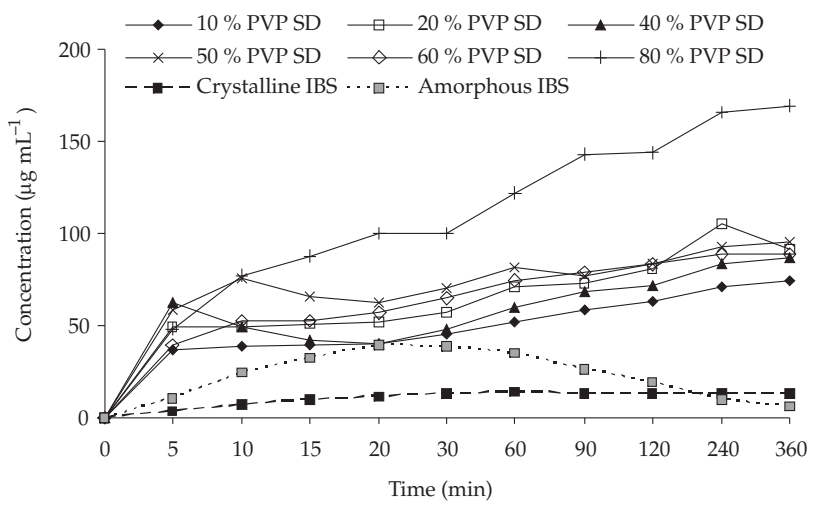

Fig. 5. Solubility profiles of SDs with different concentrations of additive: a) IBS-tartaric acid, b) IBS-PVP SD (SD bars for $n=3$ ).

additive in water. Fig. 6 shows the solubility values of the physical mixture and in pre-dissolved solutions of tartaric acid and PVP at a concentration of $20 \%(\mathrm{~m} / \mathrm{m})$. Both additives led to a significant increase in solubility of both crystalline and amorphous IBS. In the case of tartaric acid, the "acidifying " excipient, physical solubility and phase solubility values followed the order: amorphous phase solubility $>$ amorphous PM $>$ SD > crystalline phase solubility $>$ crystalline PM indicating that the amorphous state of the drug has some role to play in interaction of ionic groups of the excipient. This also confirmed the acidifying nature of tartaric acid and suggested that its role as an acidifier is less pronounced when present in molecularly dispersed state with the drug in SD. The solubility values were considerably low in crystalline PM and crystalline phase solubility. The drop in solubility peak was faster in amorphous phase solubility (30 min) compared to SD and amorphous PM (90 $\mathrm{min})$. The trend was quite different with the polymeric excipient PVP. Highest solubility was observed in SD and the lowest with crystalline PM. Amorphous phase solubility, crystalline phase solubility and amorphous PM exhibited almost similar values. This further confirmed the stabilization role (ability to keep the drug in amorphous form) played by high $T_{\mathrm{g}}$ excipients in their solid state. 
G. Chawla and A. K. Bansal: Improved dissolution of a poorly water soluble drug in solid dispersions with polymeric and non-polymeric hydrophilic additives, Acta Pharm. 58 (2008) 257-274.

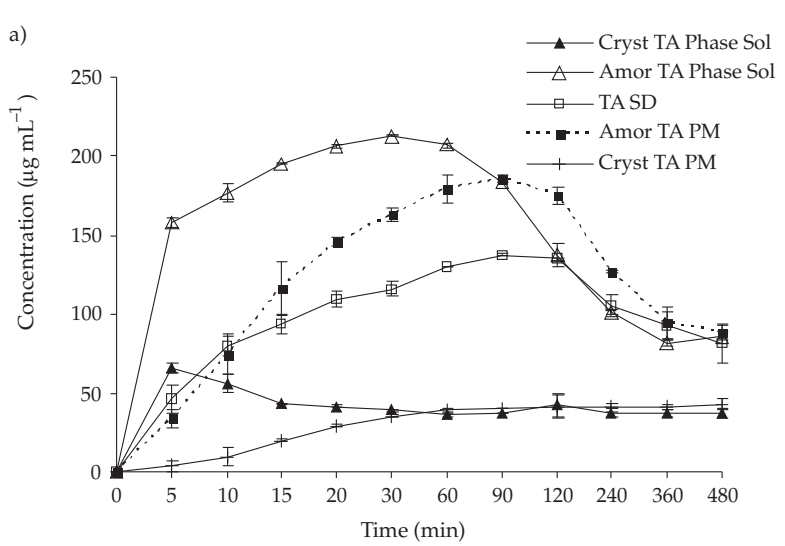

Fig. 6. Phase solubility and physical mixture solubility of IBS with: a) tartaric acid and b) PVP (SD bars for $n=$ 3).

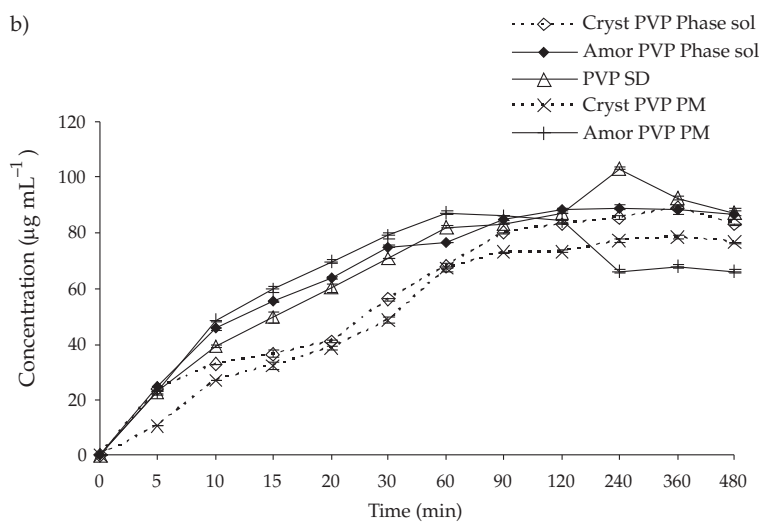

Dissolution studies at different concentrations of solid dispersions were carried out in $0.1 \mathrm{~mol} \mathrm{~L}^{-1} \mathrm{HCl}$. The trend was similar to solubility studies and the percentage released increased with increasing concentration of tartaric acid (Fig. 7). The percentage released was more than that of tartaric acid amorphous form (24\% released in $360 \mathrm{~min}$ ) even at the concentration of $10 \%(\mathrm{~m} / \mathrm{m})(31 \%$ released in $360 \mathrm{~min})$. The highest percentage release was observed at $80 \%(\mathrm{~m} / \mathrm{m})(85 \%$ in $360 \mathrm{~min})$ and more than $75 \%$ release was seen within $15 \mathrm{~min}$. The release of IBS was faster in the initial phases of dissolution at high concentrations of tartaric acid (60 and $80 \%, \mathrm{~m} / \mathrm{m}$ ). In the case of PVP, 10 and 20\% concentrations exhibited maximum release of 59 and 71\%, respectively, in $360 \mathrm{~min}$ (Fig. 7). Unlike tartaric acid, also in PVP a gradual increase was seen over the entire period of dissolution at all concentrations. No devitrification to crystalline form was observed in either case during the dissolution studies. The problem of plug formation seen in the case of pure amorphous form was not observed at concentrations higher than $40 \%$ $(\mathrm{m} / \mathrm{m})$ of the excipient.

A number of mechanisms have been proposed for the increase in the dissolution rate by SDs (5). These include reduction in size of the crystallite, solubilization effect of the carrier, absence of aggregation of crystallites, improved wettability and dispersibility 
G. Chawla and A. K. Bansal: Improved dissolution of a poorly water soluble drug in solid dispersions with polymeric and non-polymeric hydrophilic additives, Acta Pharm. 58 (2008) 257-274.
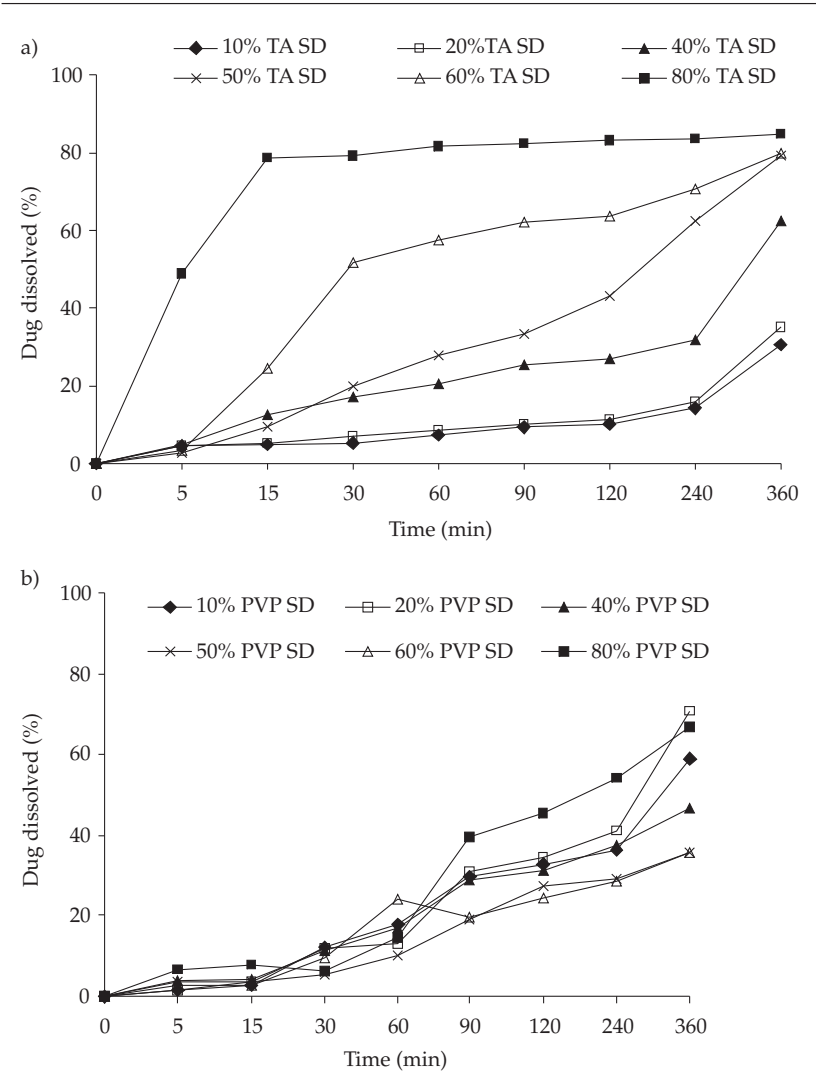

Fig. 7. In vitro dissolution studies of SDs containing different concentrations of additives: a) tartaric acid and b) PVP (SD bars for $n=3$ ).

of the drug from dispersion, drug dissolution in hydrophilic carrier, drug conversion to amorphous state, and combination of the mentioned factors. The dissolution process can be described by two distinct processes - the rate of the interfacial/solid-solvent reaction leading to solubilization of the molecule and the rate of diffusion/transport of the solvated molecule to the bulk of dissolution medium. The initial rise at higher concentrations of tartaric acid and in PVP can be due to the decrease in interfacial tension between the hydrophobic drug and the medium owing to the hydrophilic additive and local solubility effect during early stages in the drug microenvironment.

\section{CONCLUSIONS}

SDs provide a practical means of further enhancing the solubility benefit achieved using amorphous systems. IBS served as a model candidate for formation of solid solutions or dispersions of amorphous IBS into a fast dissolving matrix. The »amorphous alloys " generated using small molecules like tartaric acid and mannitol or high molecular mass polymers like PVP and HPMC led to a significant enhancement of solubility over 
G. Chawla and A. K. Bansal: Improved dissolution of a poorly water soluble drug in solid dispersions with polymeric and non-polymeric hydrophilic additives, Acta Pharm. 58 (2008) 257-274.

the crystalline form. In case of molecules that are relatively stable in their amorphous state, it was anticipated that small molecules like acids and sugars could also be used for generation of dispersions. Tartaric acid, by virtue of its $\mathrm{pH}$ altering capacity and mannitol by its water structure forming ability led to a significant improvement in solubility over crystalline IBS. High $T_{\mathrm{g}}$ polymers like PVP and HPMC, apart from their antiplasticization effect, increase the wettability and hydrophilicity of the system and maintain the molecules in the disordered state for a longer period.

Significant opportunities lie in the field of amorphous pharmaceuticals. Through an understanding of the relationship between the glassy behavior and product performance and a thorough insight into the thermodynamic and kinetic properties, it is possible to commercially utilize these molecularly disordered systems in pharmaceuticals.

Acknowledgements. - Garima Chawla acknowledges the financial support provided by the Council for Scientific and Industrial Research (CSIR), Govt. of India, as the Senior Research Fellowship for the study. Assistance provided by the Central Instrumentation Laboratory, NIPER, India, is also gratefully acknowledged.

\section{REFERENCES}

1. R. Lobenberg and G. L. Amidon, Modern bioavailability, bioequivalence and biopharmaceutics classification system. New scientific approaches to international regulatory standards, Eur. J. Pharm. Biopharm. 50 (2000) 3-12; DOI: 10.1016/S0939-6411(00)00091-6.

2. H. Yan, S. E. Tabibi and S. H. Yalkowsky, Solubilization of two structurally related anticancer drugs: XK-469 and PPA, J. Pharm. Sci. 95 (2006) 97-107; DOI: 10.1002/jps.20500.

3. L. F. Huang and W. Q. Tong, Impact of solid state properties on developability assessment of drug candidates, Adv. Drug Del. Rev. 56 (2004) 321-334; DOI: 10.1016/j.addr.2003.10.007.

4. M. Pudipeddi and A. T. M. Serajuddin, Trends in solubility of polymorphs, J. Pharm. Sci. 94 (2005) 929-939; DOI: 10.1002/jps.20302.

5. D. Q. M. Craig, The mechanisms of drug release from solid dispersions in water-soluble polymers, Int. J. Pharm. 231 (2002) 131-144; DOI: 10.1016/S0378-5173(01)00891-2.

6. G. Chawla and A. K. Bansal, A comparative assessment of solubility advantage from glassy and crystalline forms of a water-insoluble drug, Eur. J. Pharm. Sci. 32 (2007) 45-57; DOI: 10.1016/ j.ejps.2007.05.111.

7. C. J. Mbah, Kinetics of decomposition of irbesartan in aqueous solutions determined by high performance liquid chromatography, Pharmazie 59 (1994) 920-922.

8. E. Garcia, C. Hoff and S. Veesler, Dissolution and phase transition of pharmaceutical compounds, J. Crys. Growth 237-239 (2002) 2233-2239; DOI: 10.1016/S0022-0248(01)02282-5.

9. S. Veesler, L. Lafferrere, E. Garcia and C. Hoff, Phase transitions in supersaturated drug solution, Org. Process Res. Develop. 7 (2003) 983-989; DOI: 10.1021/op034089f.

10. B. Law, S. L. Krill, E. A. Schmitt, J. J. Fort, Y. Qiu, W. Wang and W. R. Porter, Physicochemical considerations in the preparation of amorphous ritonavir-poly(ethylene glycol) 8000 solid dispersions, J. Pharm. Sci. 90 (2001) 1015-1025; DOI: 10.1002/jps.1054.

11. V. B. Pokharkar, L. P. Mandpe, M. N. Padamwar, A. A. Ambike, K. R. Mahadik and A. Paradkar, Development, characterization and stabilization of amorphous form of a low Tg drug, Powder Technol. 167 (2006) 20-25; DOI: 10.1016/j.powtec.2006.05.012.

12. W. L. Chiou and S. Riegelman, Pharmaceutical applications of solid dispersion systems, J. Pharm. Sci. 60 (1971) 1281-1302; DOI: 10.1002/jps.2600600902. 
G. Chawla and A. K. Bansal: Improved dissolution of a poorly water soluble drug in solid dispersions with polymeric and non-polymeric hydrophilic additives, Acta Pharm. 58 (2008) 257-274.

13. K. Danjo, T. Nakata and A. Otsuka, Preparation and dissolution behavior of ethenzamide solid dispersions using various sugars as dispersion carriers, Chem. Pharm. Bull. 45 (1997) 1840-1844.

14. A. Forster, J. Hempenstall and T. Rades, Characterization of glass solutions of poorly water-soluble drugs produced by melt extrusion with hydrophilic amorphous polymers, J. Pharm. Pharmacol. 53 (2001) 303-315; DOI: 10.1211/0022357011775532.

15. A. Modi and P. Tayade, Enhancement of dissolution profile by solid dispersion (kneading) technique, AAPS PharmSciTech. 7 (2006) E1-E6; DOI: 10.1208/pt070368.

16. P. R. Nassab, R. Rajko and P. S. Revesz, Physicochemical characterization of meloxicam-mannitol binary systems, J. Pharm. Biomed. Anal. 41 (2006) 1191-1197; DOI: 10.1016/j.jpba.2006.02.055.

17. M. J. Arias, J. R. Moyano and J. M. Gines, Study by DSC and HSM of the oxazepam-PEG 6000 and oxazepam-D-mannitol systems: Application to the preparation of solid dispersions, Thermochim. Acta 321 (1998) 33-41; DOI: 10.1016/S0040-6031(98)00437-7.

18. P. Mura, M. T. Faucci, A. Manderioli, S. Furlanetto and S. Pinzauti, Thermal analysis as a screening technique in preformulation studies on picotinamide solid dosage forms, Drug Dev. Ind. Pharm. 24 (1998) 747-756; DOI: 10.3109/03639049809082722.

19. H. K. Chan, K. L. Au-Yeung and I. Gonda, Development of a mathematical model for the water distribution in freeze-dried solids, Pharmacol. Res. 16 (1999) 660-665; DOI: 10.1023A: 1018812305562.

20. I. Weuts, D. Kempen, A. Decorte, G. Verreck, J. Peeters, M. Brewster and G. van den Mooter, Phase behaviour analysis of solid dispersions of loperamide and two structurally related compounds with the polymers PVP-K30 and PVP-VA64, Eur. J. Pharm. Sci. 22 (2004) 375-385; DOI: 10.1016/j.ejps.2004.04.002.

21. M. Gordon and J. S. Taylor, Ideal copolymers and the second-order transitions of synthetic rubbers 1: Non-crystalline copolymers, J. Appl. Chem. 2 (1952) 493-498.

22. H. Suzuki and H. Sunada, Comparison of nicotinamide, ethylurea and polyethylene glycol as carriers for nifedipine solid dispersion systems, Chem. Pharm. Bull. 46 (1998) 482-487.

23. A. Forster, T. Rades and J. Hempenstall, Selection of suitable drug and excipient candidates to prepare glass solutions by melt extrusion for immediate release oral formulations, Pharm. Technol. (Europe) (2002) 27-37.

24. P. Sinswat, M. E. Matteucci, K. P. Johnston and R. O. Williams III, Dissolution rates and supersaturation behavior of amorphous repaglinide particles produced by controlled precipitation, $J$. Biomed. Nanotech. 3 (2007) 18-27; DOI: 10.1166/jbn.2007.001.

25. M. J. Arias, J. M. Gines, J. R. Moyano, J. I. Perez-Martinez and A. M. Rabasco, Influence of the preparation method of solid dispersions on their dissolution rate: Study of triamterene-D-mannitol system, Int. J. Pharm. 123 (1995) 25-31; DOI: 10.1016/0378-5173(95)00026-F.

\title{
$S A \check{Z} E T A K$
}

\section{Poboljšana topljivost teško topljivog lijeka u čvrstim disperzijama s polimernim i nepolimernim hidrofilnim dodacima}

\author{
GARIMA CHAWLA i ARVIND K. BANSAL
}

Irbesartan (IBS) je hidrofobni lijek teško topljiv u vodi koji se slabo oslobađa iz ljekovitih pripravaka. U radu je opisana priprava čvrstih disperzija (SDs) IBS-a pomoću aditiva male relativne molekulske mase (vinska kiselina i manitol) i polimera (polivinilpirolidona, PVP, i hidroksipropil metilceluloze, HPMC). Koristeći vinsku kiselinu i PVP 
G. Chawla and A. K. Bansal: Improved dissolution of a poorly water soluble drug in solid dispersions with polymeric and non-polymeric hydrophilic additives, Acta Pharm. 58 (2008) 257-274.

topljivost je povećana 9,5 puta $\left(138 \mu \mathrm{g} \mathrm{mL}^{-1}\right)$, odnosno 7 puta $\left(103 \mu \mathrm{g} \mathrm{mL} \mathrm{m}^{-1}\right) \mathrm{u}$ odnosu na kristaliničnu formu $\left(14,6 \mu \mathrm{g} \mathrm{mL}^{-1}\right)$. Difrakcijom X-zrakama praškastog uzorka potvrđeno je da je IBS uvijek u staklastom stanju, pa i s pomoćnim tvarima koje pri niskim temperaturama prelaze u staklasto stanje. Termičke metode (diferencijalna pretražna kalorimetrija i mikroskopija s vrućom pločom) korištene su za procjenu sposobnosti miješanja lijeka s aditivima. Rezultati ukazuju da vinska kiselina stvara amorfnu otopinu, a ostale tvari amorfne suspenzije. Oslobađanje IBS-a in vitro ovisi o količini aditiva i raste s povećanjem koncentracije vinske kiseline, (kisele pomoćne tvari). Poboljšanje topljivosti dodatkom malih molekula može se pripisati sposobnosti prelaska IBS-a u staklasto stanje i sposobnosti zadražavanja u tom stanju.

Ključne riječi: irbesartan, čvrsta disperzija, amorfno stanje, topljivost, oslobađanje

Department of Pharmaceutical Technology (Formulations), National Institute of Pharmaceutical Education and Research (NIPER), Sector 67, Phase X, S.A.S. Nagar, Punjab-160062, India 